\title{
The Consolidation Properties of Natural Fibre Clay Composite
}

\author{
Muneerah Jeludin ${ }^{1}$, Nurafiqah Suffri ${ }^{2}$, Suaidah Rahim ${ }^{3}$ \\ ${ }^{1}$ Assistant Professor, Universiti Teknologi Brunei \\ Brunei Darussalam \\ muneerah.jeludin@utb.edu.bn \\ ${ }^{2} \mathrm{Ph} . \mathrm{D}$. Candidate, Universiti Teknologi Brunei \\ Brunei Darussalam \\ nurafiqah.suffri@gmail.com \\ ${ }^{3}$ Masters Degree Candidate, Universiti Teknologi Brunei \\ Brunei Darussalam \\ suaidahar@gmail.com
}

\begin{abstract}
Settlement often occurs on weak soil due to its inability to support heavy loads which is not safe to the structures and the surroundings. In order to enhance the engineering properties of weak soil, a ground improvement technique called soil reinforcement was introduced. Soil reinforcement can be considered as economical because the reinforcement materials can be of natural fibres, hence eco-friendly. Fibres from coconut, rice husks and rhumbia are some of the natural fibres that can be found in abundance in Brunei Darussalam. In this paper, comparative study on the consolidation characteristics of soft soil reinforced with coconut husks or coir fibres at different inclusion of lengths and crushed forms were carried out on an intermediate plasticity clay obtained locally from the site of a RIPAS bridge at Sungai Kebun in Bandar Seri Begawan. The sample was first compacted to its maximum dry density in accordance to BS 1377: Part 4 to obtain its optimum moisture content for the samples preparation of consolidation tests series. The coir fibres used were in two different forms: (i) strands of 10, 20 and $30 \mathrm{~mm}$ length, and (ii) crushed form. The percentage inclusion of fibres was kept at an increment of $0.5 \%$ with a maximum of $2.0 \%$. The consolidation behaviour of these reinforced samples were observed and compared with the unreinforced sample. The results indicated that different percentage inclusion of coir fibres affects the soils' consolidation behaviour in terms of the coefficient of consolidation, $\mathrm{c}_{\mathrm{v}}$ and coefficient of permeability, $k$. The fibres inclusion also affected the soil's compression index, $\mathrm{C}_{\mathrm{c}}$ and coefficient of volume compressibility, $\mathrm{m}_{\mathrm{v}}$. From the conducted experimental investigation, it can be concluded that the soil samples reinforced with $20 \mathrm{~mm}$ length of coir fibres give the most significant effect to the soil's consolidation behaviour when it was added at $1.0 \%$.
\end{abstract}

Keywords: soft clay, consolidation, natural fibres, coir fibres, settlement.

\section{Introduction}

In Brunei Darussalam, weak and soft clays are mainly found in most areas of the country making constructions on these soils challenging. The Raja Isteri Pengiran Anak Saleha (RIPAS) bridge site in Sungkai Kebun consisted mostly of clays. As these soils are unsuitable for any construction works, they were excavated prior to construction of the bridge. Ground improvement techniques can be employed to utilise these soils for various purposes such as road pavements. One of the techniques in ground improvement is soil reinforcement. Over the years, there has been growing interest in the utilisation of natural fibres as soil reinforcement materials for the stabilisation of problematic soils especially as there is an increase in awareness of environmental issues and sustainability.

Many researchers have investigated the inclusion of reinforcement in weak soils [1-8]. The sole purpose of reinforcement in the soil matrix is to increase the strength (shearing resistance) and reduce the deformation by limiting its movement. Hence, creating a significant effect on the engineering behaviour of the soil. Fibres-reinforced soil works as a composite material where the fibres of relatively high tensile strength are inserted in the soil matrix. Shear stresses in the soil activated the tensile resistance in the fibres, which would result in a soil with a greater strength [9-12]. Randomly distributed fibres in the soils stabilize the soil mass by eliminating the potential planes of weakness imitating the performance of plant roots and hence, provide vegetation effects. 
The consolidation characteristics of fibre-reinforced clay using polypropylene fibre and coir fibre were studied using length of fibres of $10 \mathrm{~mm}, 15 \mathrm{~mm}$ and $20 \mathrm{~mm}$ [5]. A series of consolidation tests were prepared with varying fibre content of $0 \%$ to $1.0 \%$ with an increment of $0.2 \%$ in percentage of dry soil weight. Based on the experimental results obtained, the inclusion of $0.6 \%$ of polypropylene fibre and $0.8 \%$ inclusion of coir fibre to the soil gave a minimum compression index, $\mathrm{C}_{\mathrm{c}}$ value. It was also noted that the value of $\mathrm{m}_{\mathrm{v}}$ decreased with the increase in fibre inclusion of up to $0.4 \%$ polypropylene fibre and $0.6 \%$ for coir fibre. Another research on the effects of randomly distributing coconut fibres on the compressibility characteristics of fibre-reinforced soil were executed using fibre lengths of $30 \mathrm{~mm}$ and $60 \mathrm{~mm}$ at different percentage inclusions of $0 \%, 0.2 \%, 0.4 \% .0 .6 \%, 0.8 \%$ and $1.0 \%$ to the dry weight of soil [6]. The compression index, $\mathrm{C}_{\mathrm{c}}$ reduces as the fibre content increases until at a fibre content of $0.6 \%$. Beyond this, there is insignificant reduction in $\mathrm{C}_{\mathrm{c}}$ values. A linear relationship was obtained when the variation of coefficient of consolidation, $\mathrm{c}_{\mathrm{v}}$ and increasing fibre inclusion are plotted at both $30 \mathrm{~mm}$ and $60 \mathrm{~mm}$ fibre length that might be due to the constant accessibility of drainage path where the permeability of the reinforced soil was enhanced by an order of order $10^{-6} \mathrm{~cm} / \mathrm{s}$.

In another research done on a local cohesive soil (CL) randomly mixed with coir fibres, the compression index, $\mathrm{C}_{c}$ as well as the coefficient of volume change, $\mathrm{m}_{\mathrm{v}}$ decreased with increase in the fibre content [12]. A recent research conducted on Kaolin samples with different inclusions of coir fibres indicated that for coir length of $10 \mathrm{~mm}$, the compression index, $\mathrm{C}_{\mathrm{c}}$ and coefficient of volume change, $\mathrm{m}_{\mathrm{v}}$ does not show any significant reduction up to $1.5 \%$. But the reduction was observed at 1.5 and $2.0 \%$ for 20 and $30 \mathrm{~mm}$ respectively. The values of coefficient of consolidation, $\mathrm{c}_{\mathrm{v}}$ increase with the inclusion of coir fibres for length $10 \mathrm{~mm}$ and a similar behaviour could not be seen for 20 and $30 \mathrm{~mm}$ fibres. This, due to the longer length of coir, may cause uneven mixing due to insufficient friction and may cause overlapping leading to lower strength. The length of coir fibres does affect the behaviour significantly [3].

Most of the researches were done using specified lengths, none on crushed coir. With that basis, this paper attempts to compare the consolidation characteristics of locally obtained clay with random inclusions of crushed coconut fibres (coir) and with different lengths of fibres at various percentage of inclusions.

\section{Methodology}

\subsection{Materials}

Soil Sample: The clay soil used in this experiment was a slightly dark brown natural clay collected from the RIPAS Bridge site at Sungai Kebun in Bandar Seri Begawan. The local clay was obtained during the excavation land for road construction in the area. The basic characteristics of the clay soil were studied in the laboratory in accordance to BS1377: Part 2. The outcomes are tabulated in Table 1. The soil is classified as clay with intermediate plasticity (CI).

Table 1: Properties of natural soft clay.

\begin{tabular}{|l|l|}
\hline Properties & Values \\
\hline Liquid limit, LL $(\%)$ & 38.4 \\
\hline Plastic limit, PL $(\%)$ & 22.5 \\
\hline Plasticity index, PI $(\%)$ & 15.9 \\
\hline Optimum moisture content, $w_{\text {opt }}(\%)$ & 19.0 \\
\hline Maximum dry density, $\rho_{\text {dmax }}\left(\mathrm{kN} / \mathrm{m}^{3}\right)$ & 18.0 \\
\hline Specific gravity, $\mathrm{G}_{\mathrm{s}}$ & 2.70 \\
\hline BSCS classification & Intermediate plasticity \\
\hline
\end{tabular}

Reinforcement: Coir fibres are natural fibres extracted from the coconut husks which can either be brown or white fibres. Brown fibres are obtained from matured coconut having properties such as strong, thick and great resistance to 
abrasion whereas the white fibres obtained from young coconut are smoother, finer and also weaker. The best option for the reinforcement material on the local clay is the brown coir fibre. The properties of coir fibres vary and that may give difficulties to some construction due to the flexibility and rupture of the fibres. However there are many advantages of using coconut fibres in such a way that the fibres are resistant to rot and fungi, not affected by moisture, durable and tough, readily available, cost-effective (cheap) and flame-retardant.

\subsection{Sample Preparation}

Matured coconut husks were first washed, dried and decorticated to extract the brown fibres as shown in Figure 1. The coir fibres were then cut into different lengths of 10, 20 and $30 \mathrm{~mm}$, and some are crushed into powdered forms and passed through a 600 micrometres sieve size to eliminate the remaining coir strands as illustrated in Figure 2. Each type of fibres was then randomly mixed in the soft clay before adding water at its optimum amount. This is to ensure homogenous mixing of the soil and the fibres. The samples were then kept in an air tight bag for 24 hours before preparing for a series of consolidation test.

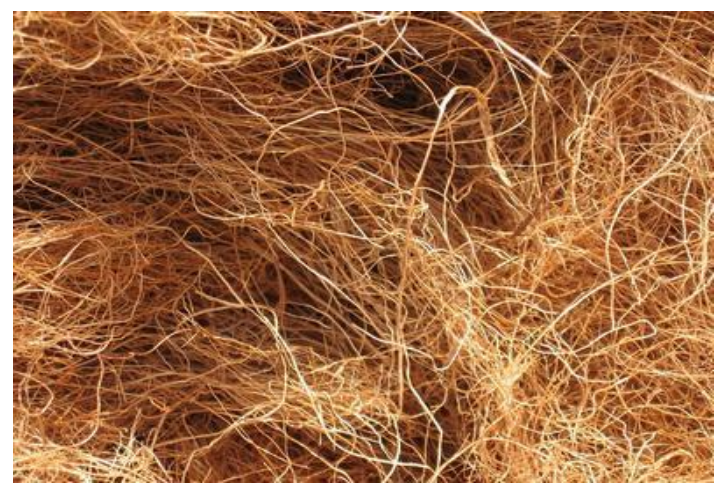

Fig. 1: Brown fibres extracted from matured coconut husks.

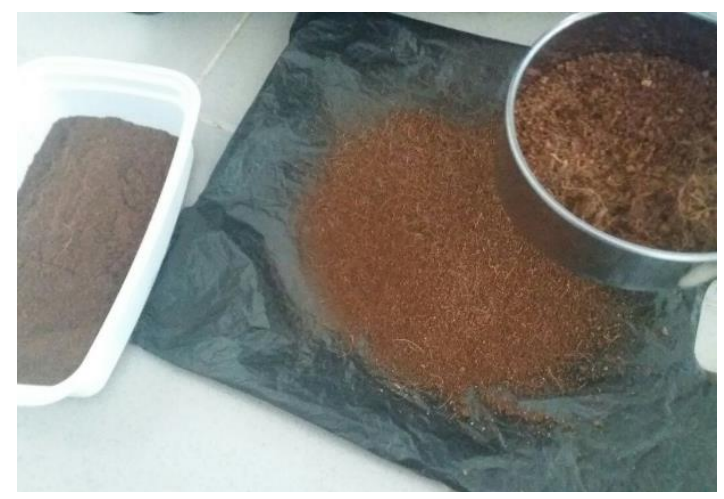

Fig. 2: Sieved crushed coir.

\subsection{Testing Programme}

The unreinforced and reinforced samples were first compacted using an automatic standard Proctor equipment according to BS 1377: Part 4 to obtain the optimum moisture content. Each sample at different percentage inclusion was then prepared at the optimum moisture content. The consolidation properties were determined by using automated one-dimensional consolidation test (Oedometer) in accordance to BS 1377: Part 5. Table 2 summarizes the testing programme for investigating the consolidation characteristics of intermediate plasticity clay soil's reinforced with crushed coir fibres and at different lengths of coir fibres. Repeat tests were performed at $1.0 \%$ and $2.0 \%$ in order to check for consistency of the results. 
Table 2: Testing programme for consolidation tests.

\begin{tabular}{|c|c|c|}
\hline Test Number & Types of Coir Fibres & $\begin{array}{c}\text { Percentage of crushed coir fibres inclusion to } \\
\text { weight of dry soil }(\%)\end{array}$ \\
\hline 1 & Unreinforced & 0.0 \\
\hline $2-5$ & $10 \mathrm{~mm}$ length & \multirow{4}{*}{$\begin{array}{l}0.5 \\
1.0 \\
1.5 \\
2.0\end{array}$} \\
\hline $6-9$ & $20 \mathrm{~mm}$ length & \\
\hline $10-13$ & $30 \mathrm{~mm}$ length & \\
\hline $14-17$ & Crushed (Powdered Form) & \\
\hline
\end{tabular}

\section{Results and Findings}

This section aims to compare the results of the one-dimensional consolidation tests of an intermediate plasticity clay reinforced with various proportions of coir in different forms; crushed and various lengths. Each result will be discussed accordingly with an attempt to evaluate and analyse the consolidation effects of the unreinforced and reinforced soft clay with different length of coir fibres and crushed coir fibres.

\subsection{Coefficient of consolidation, $c_{v}$ and time at $90 \%$ consolidation, $t_{90}$}

The method used to determine the values of the coefficient of consolidation is the Taylor's (1948) square root time method. It is indicated in Figure 3 that the coefficient of consolidation increases as the percentage inclusion increases from $0.5 \%$ to $2.0 \%$ for samples reinforced with crushed and $10 \mathrm{~mm}, 20 \mathrm{~mm}$ and $30 \mathrm{~mm}$ coir fibres. Significant improvement can be seen for the $1.0 \%$ inclusion of $20 \mathrm{~mm}$ coir fibres when compared to the unreinforced and other coir fibres inclusions. However, for samples reinforced with crushed coir fibres, the $c_{v}$ is at its highest when the soil was reinforced with $2.0 \%$ inclusions. For $10 \mathrm{~mm}$ and $20 \mathrm{~mm}$ coir fibres inclusions, the $\mathrm{c}_{\mathrm{v}}$ values decreases beyond the $1.0 \%$ inclusions. This could due to the fibres strands which may be folded during mixing with the soil samples leading to lower strength as indicated in the study by Qu and Sun [11].

From both Figures 3 and 4, it can be seen that a lower $c_{v}$ has a higher value of $t_{90}$ which explains that the soil takes a longer time to dissipate water. As fibres were included into the soil, the $\mathrm{c}_{\mathrm{v}}$ tends to increase and the $t_{90}$ decreases showing that the rate of consolidation increases. From Figure 4, the soil has the lowest t90 when it was reinforced at $1.0 \%$ of $20 \mathrm{~mm}$ coir fibres and at $2.0 \%$ of $30 \mathrm{~mm}$ fibres. The effect of the fibres introduction into the soil in terms of t 90 is very significant when compared to unreinforced soil and soil reinforced with crushed coir fibres. The addition of crushed coir fibres into the soil does give an effect in terms of $c_{v}$ and $t_{90}$ but the improvement is not as significant as the inclusion of fibres lengths into the soil sample. 


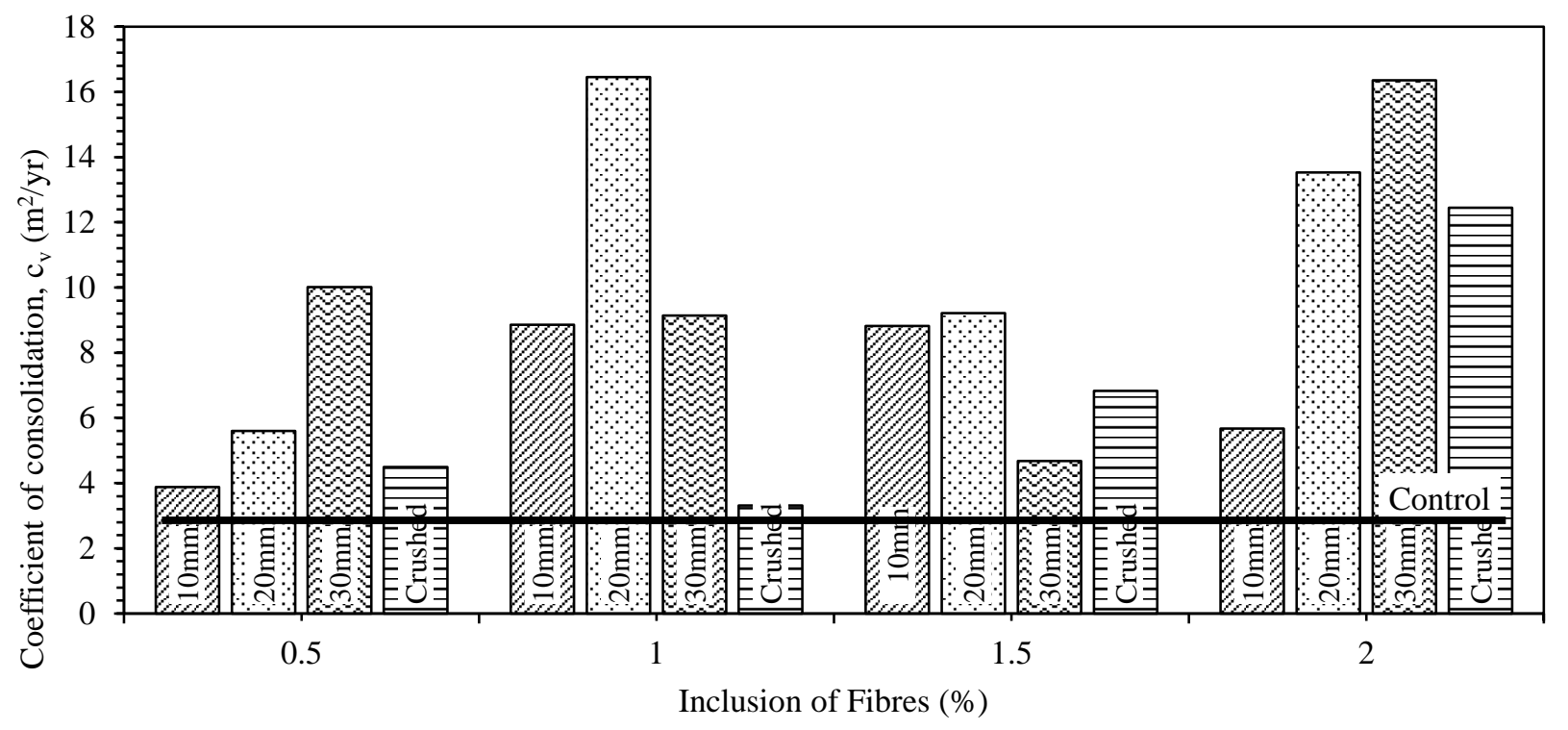

Fig. 3: Relationship between inclusion of fibres $(\%)$ and coefficient of consolidation, $\mathrm{c}_{\mathrm{v}}\left(\mathrm{m}^{2} / \mathrm{yr}\right)$.

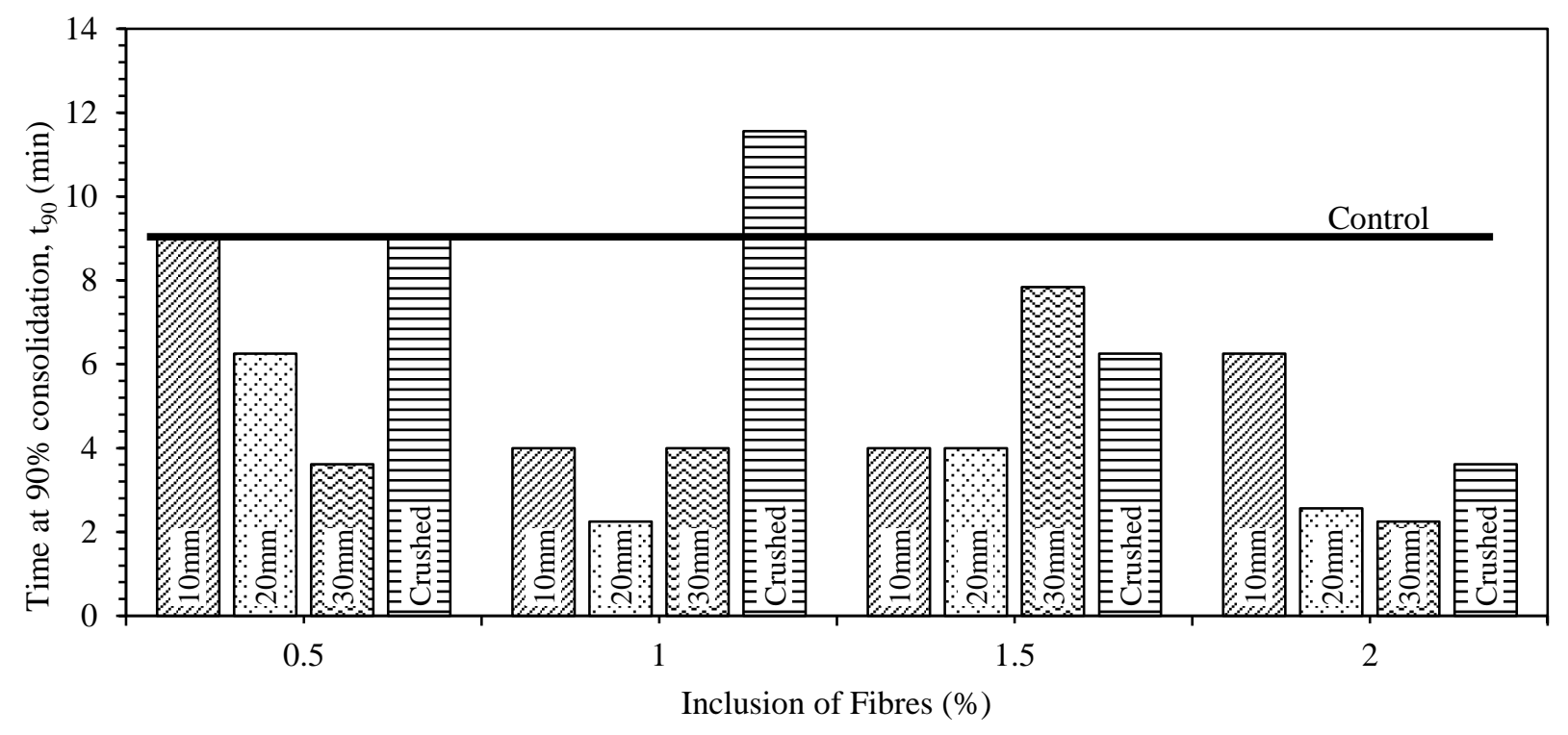

Fig. 4: Relationship between inclusion of fibres $(\%)$ and time at $90 \%$ consolidation, $\mathrm{t}_{90}(\mathrm{~min})$.

\subsection{Compression index, $\mathrm{C}_{\mathrm{c}}$ and coefficient of volume compressibility, $\mathrm{m}_{\mathrm{v}}$}

It was found that the compression index, $\mathrm{C}_{\mathrm{c}}$ as shown in Figure 5 for samples reinforced with coir fibres decreases with the inclusion of coir fibres at $0.5 \%$ both for crushed coir, $10 \mathrm{~mm}$ and $20 \mathrm{~mm}$ lengths of coir fibres. However, for $30 \mathrm{~mm}$ the optimum reduction of compression index, $\mathrm{C}_{\mathrm{c}}$ was at $1.0 \%$ inclusion. Beyond this content, the compression index, $\mathrm{C}_{\mathrm{c}}$ for all reinforced samples slightly increases.

From Figure 6, it is observed that the values for coefficient of volume change, $\mathrm{m}_{\mathrm{v}}$ of the soil have a similar trend with that of the compression index except for the fibres inclusion at $2.0 \%$. The increment of $\mathrm{m}_{\mathrm{v}}$ for $20 \mathrm{~mm}$ coir fibres might be 
caused by the stronger bonds between fibre and soil which increases the resistance of soil against compression as indicated in the study obtained by Kar et al [5]. Therefore, further enhancing the strength of soil-fibre mixture and reduced settlement.

The increase in $C_{c}$ and $m_{v}$ values at certain extent when included with coir fibres could be due to the reason that the coir fibres behave as a binder to the soil particles and thus, the resistance of the soil to compression increases. The result in this investigation agreed with Kar et al [5] where they observed that the increase might be due to more fibre-to-fibre interaction as more volume occupied by the fibre and thus the compression of the fibre will be dominant with increasing fibre inclusion.

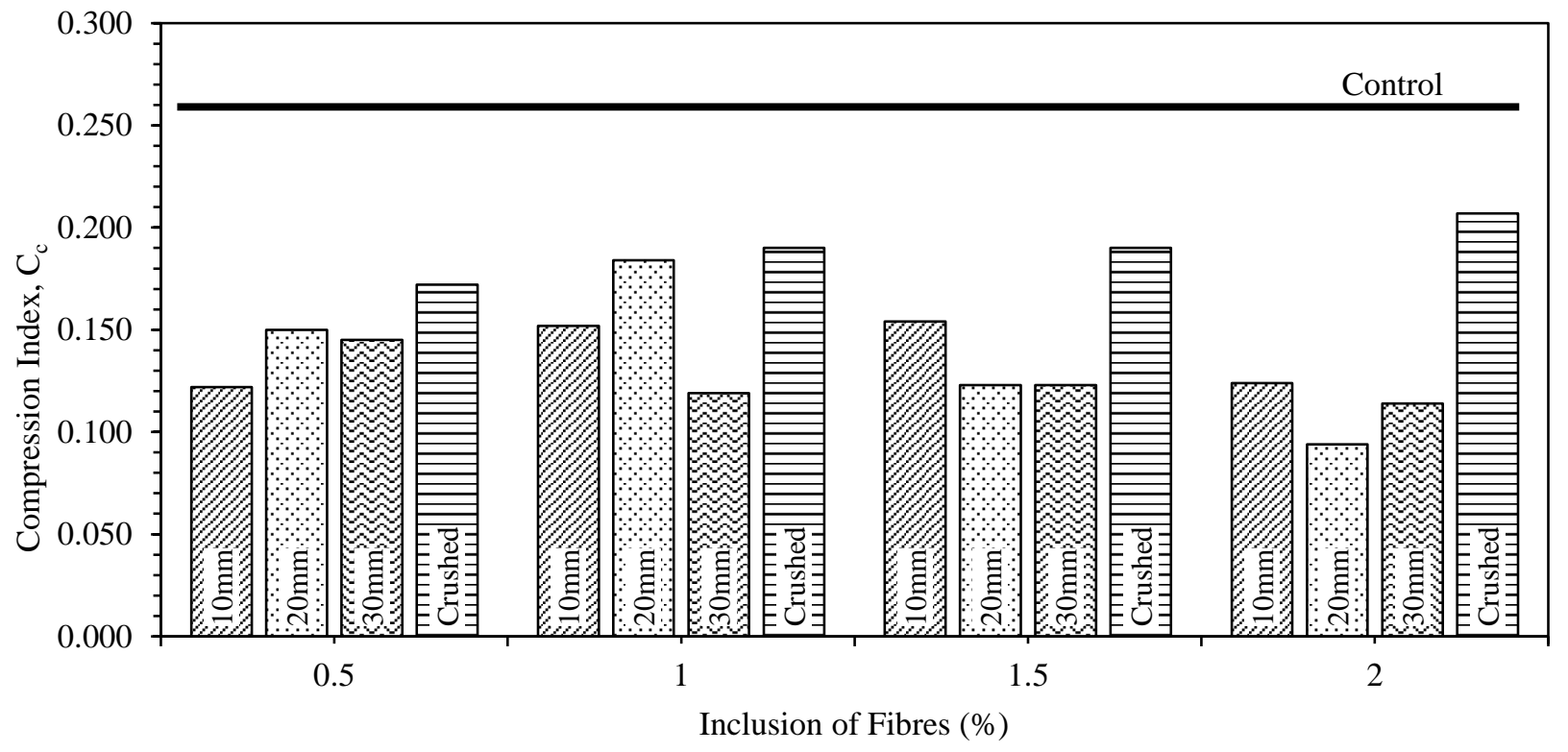

Fig. 5: Relationship between inclusion of fibres (\%) and compression index, $\mathrm{C}_{\mathrm{c}}$.

\subsection{Coefficient of permeability, $k$}

Figure 7 presents the relationship between the coefficient of permeability, $k$ and the inclusion of coir fibres at various percentage. It can be observed that increase in coir fibres inclusion increases the coefficient of permeability, $k$ except for $0.5 \%$ inclusion of $10 \mathrm{~mm}$ coir, $1.0 \%$ of crushed coir and $1.5 \%$ of $30 \mathrm{~mm}$ coir. The increase in permeability could be due to a better interlocking between the soil particles and the coir fibres. This in turn increases the average size of the pores leading to a faster permeability. However, at $1.0 \%$ inclusion of $20 \mathrm{~mm}$ fibres, a greater increment on the coefficient of permeability can be seen. This pattern is similar to the effects of coir fibres on the coefficient of consolidation, $c_{v}$. The reason could be due to the clumping of soil particles which create inappropriate distribution of fibres resulting in an inadequate average pore size, thus having a low permeability. 


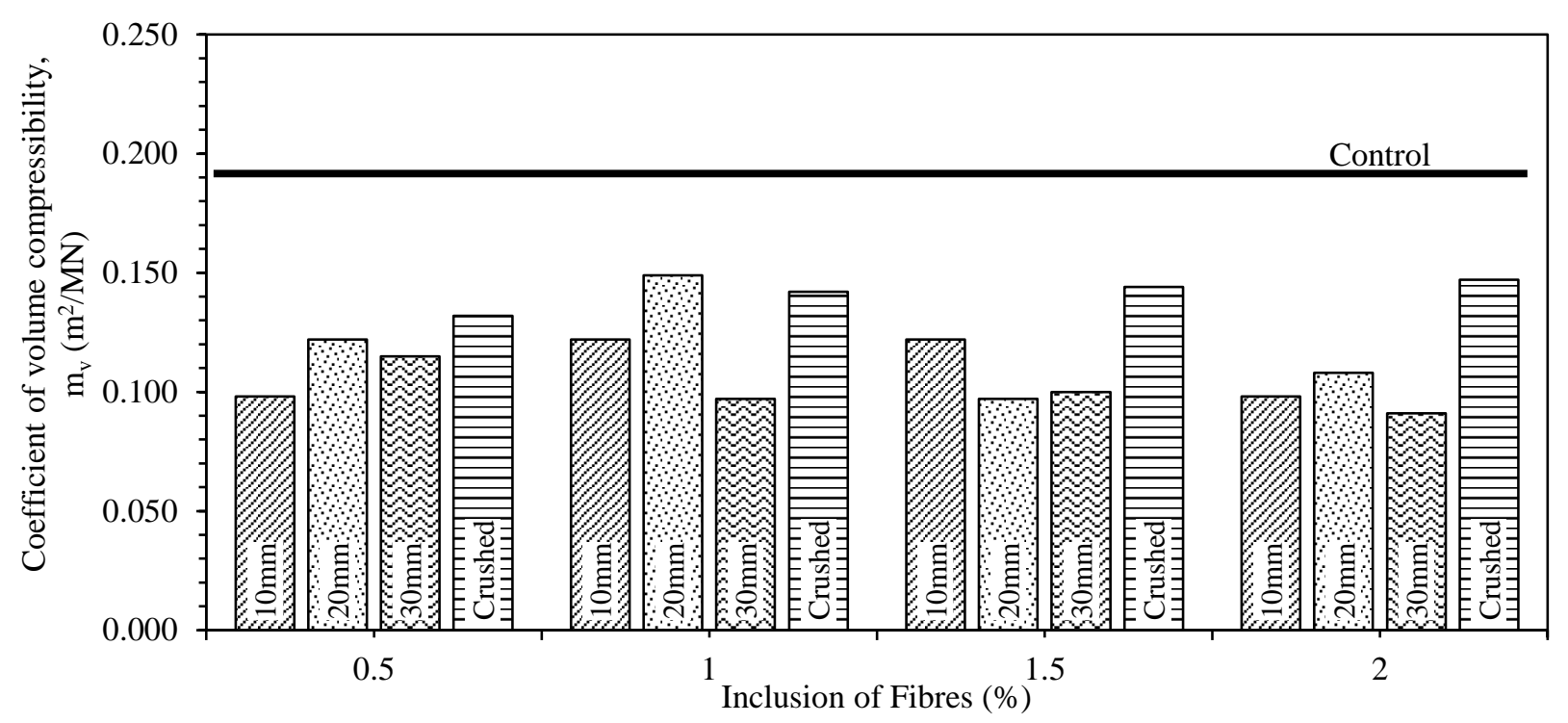

Fig. 6: Relationship between inclusion of fibres (\%) and coefficient of volume compressibility, $\mathrm{m}_{\mathrm{v}}\left(\mathrm{m}^{2} / \mathrm{MN}\right)$.

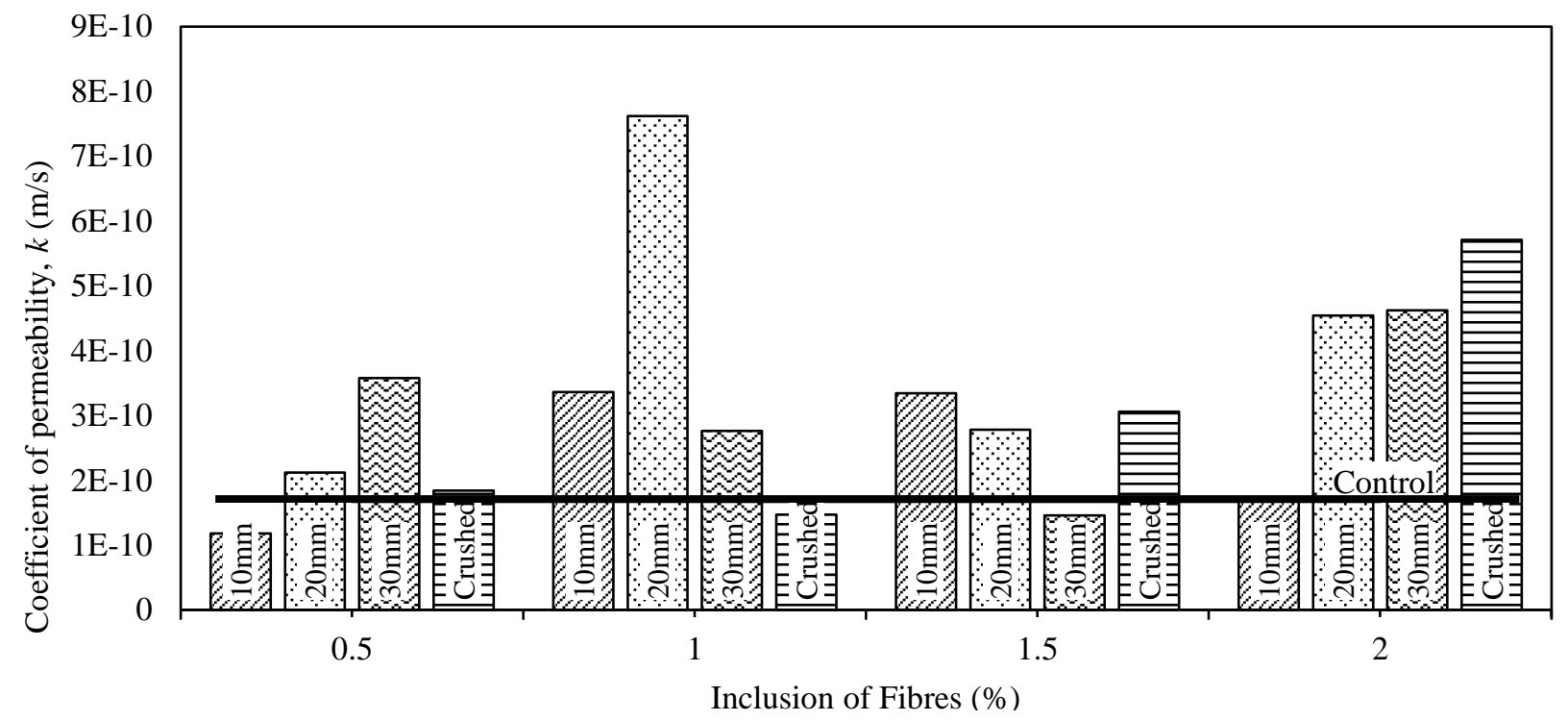

Fig. 7: Relationship between inclusion of fibres (\%) and coefficient of permeability, $k(\mathrm{~m} / \mathrm{s})$. 


\section{Conclusion}

This study compares the effects of coir fibre inclusion; crushed fibres and of different lengths on the consolidation behaviour of clay samples. The coefficient of consolidation, $\mathrm{c}_{\mathrm{v}}$ and coefficient of permeability, $k$ show significant increment up to $1.0 \%$ for $10 \mathrm{~mm}$ and $20 \mathrm{~mm}$, and $2.0 \%$ for both $30 \mathrm{~mm}$ coir fibres and crushed coir fibres. Increasing the percentage of fibres inclusion therefore increased the value of permeability coefficient. However the reduction in $k$ values for all fibres inclusion is still higher than that of the unreinforced sample except for the inclusions at $0.5 \%$ of $10 \mathrm{~mm}$ coir, $1.0 \%$ of crushed coir and $2.0 \%$ of $30 \mathrm{~mm}$ coir fibres.

The values of compression index, $\mathrm{C}_{\mathrm{c}}$ and coefficient of volume compressibility, $\mathrm{m}_{\mathrm{v}}$ increase with the increase in fibres inclusion up to $1.5 \%$ for $10 \mathrm{~mm}$ coir fibres. However, for 20 and $30 \mathrm{~mm}$ similar behaviour could not be seen. This, due to the longer length of coir, may cause uneven mixing due to insufficient friction and may cause overlapping leading to lower strength. The length of coir fibres does affect the behaviour significantly. For samples reinforced with crushed coir fibres, the values of $\mathrm{C}_{\mathrm{c}}$ and $\mathrm{m}_{\mathrm{v}}$ increase steadily with the increase in percentage inclusions. Two repeat tests were conducted to check for the consistency of results obtained and it was confirmed that the results produced were similar and consistent with that of the first experiments. It can be seen that the effects on consolidation are significant when the soil samples were reinforced with coir fibres. However the ultimate improvement of the coefficient of consolidation was observed at $1.0 \%$ inclusion of $20 \mathrm{~mm}$ length of coir fibres.

\section{Acknowledgements}

The authors would like to thank Universiti Teknologi Brunei and also the Civil Engineering programme area at the Faculty of Engineering for providing facilities to carry out the research.

\section{References}

[1] N. Quang and P. Giao, "Improvement of soft clay at a site in the Mekong Delta by vacuum preloading," Geomechanics and Engineering, vol. 6, no.5, pp. 419-436, 2014.

[2] S. Hejazi, M. Sheikhzadeh, S. Abtahi, and A. Zadhoush, "A simple review of soil reinforcement by using natural and synthetic fibres," Construction and Building Materials, vol. 30, pp. 100-116, 2012.

[3] M. Jeludin and N. Suffri, "The Effects of Coir Fibre on Consolidation Behaviour of Soft Clay," GCEC 2017: Proceedings of the 1st Global Civil Engineering Conference, vol. 9, pp. 1323-1330, 2018.

[4] S. Nahta, and N. Vibhakar, "Study of the Effect of Coir Fibre Reinforcement on the Strength Parameters and CBR Value of Clayey Soil," International Journal of Engineering Research \& Technology (IJERT), vo. 3, no. 4, 2014.

[5] R. K. Kar, P. K. Pradhan, A. Naik, "Consolidation Characteristics of Fibre Reinforced Cohesive Soil," Electronic Journal of Geotechnical Engineering, vol. 17, pp. 3861-3874, 2012.

[6] A. Lawer and S. Boadu, "Compressibility characteristics of coconut fibre reinforced lateritic subgrade soil," Proceedings of the 6th International Young Geotechnical Engineers' Conference (iYGEC6), 2017.

[7] A. Gaikwad and V. Sharma, "Comparative Study of Coir fibre to reinforce soil," International Journal of Modern Trends in Engineering and Research, vol. 2349, pp. 732-738, 2015.

[8] J. Manzoor and T. Leander "Effect of Bamboo Fibre on Marine Clay," International Research Journal of Engineering and Technology (IRJET), vol. 4, no. 11, pp. 2073-2075, 2017.

[9] R. Ayothiraman and A. Singh, "Improvement of Soil Properties by Basalt Fibre Reinforcement," DFI-PFSF 2017 Conference, Melbourne, pp. 403-412, 2017.

[10] G. Sivakumar Babu and A. Vasudevan, "Strength and Stiffness Response of Coir Fibre-Reinforced Tropical Soil," Journal of Materials in Civil Engineering, vol. 20, no. 9, pp. 571-577, 2008.

[11] J. Qu and Z. Sun, "Strength Behaviour of Shanghai Clayey Soil Reinforced with Wheat Straw Fibres," Geotechnical and Geological Engineering, vol. 34, no. 2, pp. 515-527, 2015.

[12] P. K. Pradhan, R. K. Kar, and A. Naik, "Effect of Random Inclusion of Polypropylene Fibers on Strength Characteristics of Cohesive Soil," Geotechnical and Geological Engineering, vol. 30, no. 1, pp. 15-25, 2011. 
[13] B. Asha, B. Ram Rathan Lal, A. Padade, T. Mandal and J. Nath Mandal, "Emerging Trends in Ground Improvement Techniques," in GeoCongress 2012. Geotechnical Special Publication, 2012.

[14] G. Tjie-Liong, M. Irsyam and A. Gunawan, "The Application of Ground Improvement Techniques in Indonesia," in 18th Southeast Asian Geotechnical Conference (18SEAGC) \& Inaugural AGSSEA Conference (1AGSSEA). Singapore: Research Publishing, 2013.

[15] A. Arulrajah, A. Abdullah, M. Bo, and A. Bouazza, "Ground improvement techniques for railway embankments," Proceedings of the Institution of Civil Engineers - Ground Improvement, vol. 162, no. 1, pp. 3-14, 2009.

[16] H. Vidal, “The Principle of Reinforced Earth,” National Academy of Sciences (US), vol. 282, pp.1-16, 1969. 